\title{
PRAZER E SOFRIMENTO NO TRABALHO DE DOCENTES DE ENFERMAGEM: REVISÃO INTEGRATIVA
}

\author{
PLEASURE AND SUFFERING IN NURSING TEACHERS' WORK: INTEGRATIVE REVIEW
}

\author{
Marcelo Nunes da Silva Fernandes ${ }^{a}$, Luis Felipe Dias Lopes ${ }^{b}$, Daniel Arruda Coronelc, \\ Teresinha Heck Weiller ${ }^{d}$, Viviani Viero ${ }^{e}$, Paula Hübner Freitas ${ }^{f}$ \\ amarcelonsf@gmail.com, blflopes67@yahoo.com.br, cdaniel.coronel@uol.com.br, dweiller2@hotmail.com, eviviviero@hotmail.com, \\ fenf.paulahf@gmail.com \\ Universidade Federal de Santa Maria - Santa Maria (RS), Brasil
}

Data de recebimento de artigo: 17/03/2017

Data de aceite do artigo: 26/07/2017

\section{RESUMO}

Introduçáo: $\mathrm{O}$ trabalho tem sido considerado elemento fundamental na sociedade e uma categoria central na vida dos homens. Objetivo: Evidenciar nas produçóes científicas os fatores que geram prazer e sofrimento na docência de enfermagem. Método: Trata-se de uma revisão integrativa realizada nas bases de dados Literatura Latino-Americana em Ciências de Saúde, Literatura Internacional em Ciências da Saúde e Dados Bibliográficos na Área de Enfermagem do Brasil, no período de agosto a setembro de 2015, utilizando-se como descritores "enfermagem", "prazer", "sofrimento" e "docentes". A amostra constituiuse de quatro artigos, sem recorte temporal. Resultados: Os principais fatores de prazer na docência de enfermagem são a interação entre docente e aluno, como também a valorização e o reconhecimento profissional, sendo o principal fator de sofrimento o relacionamento interpessoal. Conclusáo: Constatouse que tais sentimentos aparecem interligados, pois são fortemente influenciados pelas relaçôes no trabalho. Destaca-se que é imprescindível preocupar-se com a saúde do docente de enfermagem, com vistas a ressignificar os fatores de sofrimento, buscando novos sentidos para seu ofício, os quais possam culminar em prazer e satisfação.

Palavras-chave: Enfermagem; saúde do trabalhador; docentes.

\section{ABSTRACT:}

Introduction: Work has been considered a fundamental element in society and a central category in the human life. Objective: Aimed to highlight in the scientific production factors that generate pleasure and suffering at work of nursing teachers. Method: This is an integrative review conducted in the databases Latin American Literature in Health Sciences, International Literature in Health Sciences and Bibliographic Data on Brazil Nursing area in the period from August to September 2015, using as descriptors nursing, pleasure, sorrow and teachers. Results: The sample consisted of four articles without time frame. The main pleasure factors in the work of nursing faculty are the interaction between teacher and student, besides the enhancement and professional recognition and the main factor is the suffering of interpersonal relationships. Conclusion: It was observed that these feelings appear interconnected because they are strongly influenced by the relationships in the work. It should be emphasized that it is imperative to care about the health of the nursing teacher, in order to give a new significance to the factors of suffering, seeking new meanings for their work, which can culminate in pleasure and satisfaction.

Keywords: Nursing; occupational health; faculty. 


\section{Introdução}

O trabalho tem sido considerado elemento fundamental na sociedade contemporânea, sobrepondo-se à ideia puramente de tarefa, ocupaçáo ou meio de sobrevivência, sendo visto, cada vez mais, como categoria central na vida dos homens. Corroborando essa ideia, ele se torna cada vez mais significativo na vida das pessoas, conferindo inclusive identidade ao homem ${ }^{1}$. Nessa perspectiva, a saúde é vista como expressão de uma integridade física, psicológica e social marcada pelo emprego de mediaçôes capazes de mobilizar aqueles que o exercem na busca de uma relação mais gratificante com o trabalho ${ }^{2}$. Assim, sendo ele fundamental na vida do homem, por ser o meio pelo qual este se insere na sociedade, pode desencadear sentimentos de prazer e satisfação, mas também de sofrimento e fadiga ${ }^{3}$.

Com vistas à temática do prazer e do sofrimento nesse meio, afunila-se o mundo laboral para o contexto da docência. Esse ofício traz consigo a missão de disseminar conhecimento e formar mão de obra especializada ${ }^{4}$. Porém, na contemporaneidade, à docência passou de um caráter mais prescritivo para uma atividade de interaçóes humanas ${ }^{5}$. Nessa perspectiva, se faz necessário compreender a relaçáo do exercício da docência especialmente no que diz respeito ao prazer e ao sofrimento, uma vez que essa profissãotem apontamentos de ser uma das mais propensas ao sofrimento psíquico ${ }^{6}$. A docência, de modo geral, é complexa, já que os profissionais que a exercem se encontram em uma realidade na qual devem atender à formação integral dos alunos, possibilitando o conhecimento científico, a comunicação e o raciocínio lógico, por meio de uma formação psicológica, afetiva e emocional ${ }^{7}$.

Altas demandas têm impactado a qualidade de vida dos professores ${ }^{8}$. Assim, existem fatores implicados na relação entre o ofício e saúde do docente, destacando-se a intensificação do serviço, a precarização das relações de emprego e as mudanças nas relaçóes de trabalho?. Em contraponto, há a necessidade de maior liberdade no exercício profissional para que este opere como fonte de saúde, possibilitando identificar os fatores que desencadeiam prazer. Assim, os docentes vivenciam um paradoxo em relação aos sentimentos suscitados, havendo, de um lado, vivências de sofrimento que podem estar atreladas à precarização das condiçóes e das relaçóes de trabalho e, de outro, as vivências do prazer vinculadas à produçáo de conhecimento, às relaçóes afetivas e ao reconhecimento que o espaço acadêmico possibilita ao docente ${ }^{10}$.

Nesse sentido, a fim de aprofundar conhecimentos sobre a temática, buscou-se realizar uma revisão integrativa, com a intenção de responder ao seguinte questionamento: quais os fatores que geram prazer e sofrimento na docência de enfermagem? E, como objetivo geral, evidenciar nas produçóes científicas esses fatores. Este artigo está organizado em cinco seçôes, contando com esta introdução. $\mathrm{Na}$ próxima seção, o referencial teórico será apresentado; depois, na terceira, os procedimentos metodológicos serão descritos; na seguinte, os resultados serão discutidos e analisados; por fim, as principais consideraçôes depreendidas serão expostas.

\section{Referencial téorico}

A psicodinâmica do trabalho propõe compreender a relação subjetiva dos profissionais com o seu ofício, enfocando a questáo de como determinado contexto oportuniza aos profissionais o uso de estratégias para mediar as restriçóes, pressões e adversidades advindas do trabalho ${ }^{2,11}$. Este se torna ameaçador para o aparelho psíquico quando se opóe à sua livre atividade. Nesse sentido, um ofício compatível com as necessidades do trabalhador constitui-se como equilibrante e, quando se opóe aos desejos deste, denomina-se fatigante ${ }^{12}$.

A presença do sofrimento não implica patologia, mas as circunstâncias do trabalho podem desencadear perturbaçóes psicossomáticas e psíquicas, uma vez que não há mais possibilidades de negociação entre o sujeito e a realidade para ressignificar o sofrimento e gerar condiçôes para modificar o contexto de trabalho' ${ }^{2}$. Nesse contexto, existem dois tipos de sofrimento originados na organização do trabalho: o patogênico e o criativo. $\mathrm{O}$ primeiro origina o desequilíbrio psíquico do servidor e, por conseguinte, a manifestação da doença, enquanto o outro, por sua vez, acontece quando o profissional consegue elaborar soluções que favoreçam a sua saúde ${ }^{12,13}$.

Ainda, o sofrimento transformado em criatividade beneficia a identidade do profissional e aumenta sua resistência ao risco de desestabilização psíquica e somática. Entretanto, quando as relaçôes sociais de trabalho e as escolhas gerenciais empregam o sofrimento, o ofício se transforma em um mediador da desestabilização e da fragilização da saúde ${ }^{12}$. Esse sofrimento acontece do encontro entre o profissional enquanto sujeito, considerando sua trajetória de vida, com a organização do trabalho que prescreve um modo operatório específico a quem o exerce. Assim, tal organizaçáo se opõe ou até mesmo se impóe ao profissional, pois compreende a divisão da atividade profissional, o conteúdo da tarefa, o sistema hierárquico, as relaçôes de poder, entre outras ${ }^{12,14}$.

Nesse sentido, a organização do trabalho pode ser de dois tipos: o prescrito, que corresponde às prescriçôes impostas pela organização ao profissional para a operacionalização dos serviços e o real, que se relaciona ao que de fato o profissional executa ${ }^{15}$. Corroborando, o prescrito é aquele que deve ser feito pelos servidores seguindo 
normas e definições precisas, enquanto o real é aquele que foge à prescrição, é algo imprevisto, inesperado, que o trabalhador deve dar conta. Assim, dessa defasagem existente entre os dois, emergem aspectos que podem ser fonte de prazer ou de sofrimento ao exercer atividades profissinais ${ }^{16}$.

Com relação ao prazer, este pode derivar da ressignificação do sofrimento e da transformação do contexto de trabalho. Também pode ser resultado direto do ofício, quando existe compatibilidade entre as necessidades e os desejos do profissional e da organização do exercício do servidor. Ainda, a obtenção do prazer pode derivar do mecanismo de mobilização subjetiva, isto é, o processo pelo qual os trabalhadores lançam mão dos seus recursos intelectuais e da sua subjetividade para transformar as situaçôes geradoras de sofrimento em geradoras de prazer, permitindo o resgate do sentido de exercer as funçóes do serviço ${ }^{17}$.

Nesse sentido, o prazer emerge quando são experimentados sentimentos de valorização e de reconhecimento na prática profissional, sendo a valorizaçáo o sentimento de que o trabalho tem sentido e valor por si mesmo, enquanto o reconhecimento provém da sensaçáo de ser aceito, admirado profissionalmente e ter liberdade para expressar sua individualidade ${ }^{18}$. Com essa leitura, reconhece-se a utilidade dessa abordagem teórica no estudo das vivências de prazer e de sofrimento no trabalho.

\section{Método}

A fim de atingir o objetivo proposto, optou-se por realizar uma pesquisa de abordagem qualitativa que buscou evidenciar nas produçóes científicas os fatores que geram prazer e sofrimento no trabalho de docentes de enfermagem, por meio de um modelo de revisão integrativa da literatura ${ }^{19}$. Segundo as autoras, a revisão integrativa de literatura tem a finalidade de reunir e sintetizar resultados de pesquisas sobre um tema ou uma questáo de maneira sistemática e ordenada ${ }^{20}$. Corroborando, esse tipo de revisáo permite uma compreensão mais completa do fenômeno analisado, a partir de propósitos acerca de uma temática, bem como a possibilidade de gerar novas perspectivas sobre o fenômeno estudado e apontar lacunas do conhecimento para a realização de novos estudos ${ }^{20}$.

Desse modo, para a construção da revisão integrativa, seguem-se seis etapas distintas, quais sejam: identificação do tema e seleção da hipótese ou questâo de pesquisa; estabelecimento de critérios para inclusão e exclusão de estudos/amostragem ou busca na literatura; definição das informaçōes a serem extraídas dos estudos selecionados/categorização dos estudos; avaliação dos estudos incluídos na revisão integrativa; interpretação dos resultados; apresentação da revisão/ síntese do conhecimento ${ }^{19}$. Portanto, para a concretização desta revisão integrativa, foram obedecidas criteriosamente as etapas mencionadas, no período de agosto a setembro de 2015. Os critérios adotados para inclusão dos estudos foram: artigos de pesquisa, na íntegra, disponibilizados nos idiomas português, inglês ou espanhol, que abordassem a temática pesquisada e se encontrassem disponíveis on-line e gratuitos, sem recorte temporal e relacionados à área da docência de enfermagem. Os estudos encontrados em mais de uma base de dados ou na mesma base foram considerados somente uma vez, sendo assim excluídos os artigos duplicados.

As bases de dados utilizadas para a busca foram: Literatura Latino-Americana em Ciências de Saúde (Lilacs); Literatura Internacional em Ciências da Saúde (Medline) e Dados Bibliográficos na Área de Enfermagem do Brasil (BDENF). O recurso utilizado na pesquisa foi a opção "palavras": "prazer" and "sofrimento" and "enfermagem" and "docentes", nas bases Lilacs e BDENF, sendo realizada a mesma busca com as palavras na versão em inglês, na base Medline, para a captura de artigos internacionais, que não apareciam ao procurar em português.

A busca pelas produçóes resultou inicialmente nos seguintes números nas referidas bases de dados: 1 resultado na Medline, 5 na Lilacs e 8 na BDENF, totalizando 14 resultados. Após a captação de todos os artigos, passou-se à leitura dos títulos e resumos, primeiramente realizando a exclusão dos artigos duplicados em mais de uma base de dados ou na mesma base, considerando apenas uma das versóes, permanecendo, desse modo, com 1 resultado na Medline, 4 na Lilacs e 2 na BDENF, totalizando 7 resultados. Na sequência, foram selecionados apenas os artigos de pesquisa, na íntegra, disponíveis on-line e gratuitos, restando 1 resultado na Medline e 3 na Lilacs, total de 4 resultados. Posteriormente, buscou-se excluir os artigos que não estavam adequados à temática e suprimir os artigos que não se encontravam nos idiomas português, inglês ou espanhol, restando os mesmos 4 artigos, os quais constituíram o corpus desta revisão.

Para análise dos estudos, utilizou-se a Análise de conteúdo ${ }^{21}$, que consiste em três etapas: pré-análise, exploração do material e interpretação dos resultados. As duas primeiras permitiram uma visão abrangente do conteúdo dos artigos por meio de leitura. Na etapa de interpretação dos resultados, esses foram discutidos com base em diferentes autores ${ }^{21}$. No que tange à dimensão ética do estudo, este é de natureza bibliográfica e por isso não tramitou pelo Comitê de Ética em Pesquisa (CEP). Entretanto, os preceitos de autoria foram respeitados. 


\section{Resultados e discussão}

Os anos de publicação dos artigos foram 2005, 2006, 2007 e 2009. Quanto à área de publicação, constatou-se que a enfermagem foi a responsável pelos textos publicados. Já em relaçáo aos sujeitos pesquisados, os estudos foram realizados com a participação de enfermeiros docentes. Com relação ao delineamento, os estudos foram classificados no nível de evidência 6 , isto é, "evidências provenientes de um único estudo descritivo ou qualitativo", conforme a classificação de $2005^{22}$, adotada como referência nesta revisão integrativa. Os artigos versavam sobre a temática escolhida, sendo possível constatar algumas evidências relacionadas ao prazer e ao sofrimento na docência de enfermagem.

Para a coleta de dados, o método empregado nos dois estudos de abordagem qualitativa foi a entrevista, enquanto o instrumento utilizado nos dois estudos de abordagem quantitativa foi uma escala do tipo Likert. Em relação ao método de análise dos dados, a análise de conteúdo utilizada nos artigos de abordagem qualitativa foi a metodológica. No Quadro 1, apresenta-se os artigos que constituem o corpus desta revisão integrativa, destacando-se a base de dados em que foram encontrados, a referência, o objetivo, o delineamento e os resultados dos estudos.

Quadro 1: Apresentação dos artigos que constituem o corpus desta revisão integrativa.

\begin{tabular}{|c|c|c|c|c|c|c|}
\hline Código & Ano & $\begin{array}{l}\text { Base de } \\
\text { dados }\end{array}$ & Referência & Objetivo & Delineamento & Resultados \\
\hline A1 & 2009 & Lilacs & Ferreira et al. ${ }^{23}$ & $\begin{array}{l}\text { Identificar os aspectos } \\
\text { geradores de prazer e de } \\
\text { sofrimento no processo } \\
\text { de trabalho do enfermei- } \\
\text { ro docente. }\end{array}$ & $\begin{array}{l}\text { Trata-se de um estudo } \\
\text { exploratório e descritivo } \\
\text { com abordagem qualita- } \\
\text { tiva. Uso de entrevista e } \\
\text { análise de conteúdo. }\end{array}$ & $\begin{array}{l}\text { O prazer surge da interação entre } \\
\text { docente e aluno, engajamento com as } \\
\text { atividades didático-pedagógicas e o } \\
\text { compromisso com a formaçáo profis- } \\
\text { sional. O sofrimento surge quando há } \\
\text { uma desarticulação entre o empenho do } \\
\text { docente e do aluno, marcado por de- } \\
\text { sinteresse ou descompromisso, questóes } \\
\text { relacionadas à organização do trabalho e } \\
\text { ao relacionamento interpessoal. }\end{array}$ \\
\hline $\mathrm{A} 2$ & 2007 & Lilacs & $\begin{array}{l}\text { Carbogim e } \\
\text { Gonçalves }^{24}\end{array}$ & $\begin{array}{l}\text { Identificar o significado } \\
\text { do trabalho para os } \\
\text { docentes e os fatores } \\
\text { relacionados ao desgaste } \\
\text { psíquico no trabalho, } \\
\text { bem como verificar } \\
\text { como convivem com } \\
\text { o sofrimento/prazer na } \\
\text { docência. }\end{array}$ & $\begin{array}{l}\text { Trata-se de um estudo } \\
\text { qualitativo. Uso de } \\
\text { entrevista e análise de } \\
\text { conteúdo. }\end{array}$ & $\begin{array}{l}\text { O significado de ser docente envolve } \\
\text { reconhecimento pessoal, missão e troca } \\
\text { de experiências. O sofrimento está } \\
\text { relacionado a: falta de recursos materiais } \\
\text { e humanos; sobrecarga de trabalho; } \\
\text { baixos salários; desconforto do ambiente } \\
\text { físico; relaçóes interpessoais; falta de } \\
\text { privacidade. }\end{array}$ \\
\hline A3 & 2005 & Lilacs & $\begin{array}{l}\text { Martins e } \\
\text { Robazzi }^{25}\end{array}$ & $\begin{array}{l}\text { Verificar se as enfermei- } \\
\text { ras docentes vivenciam } \\
\text { sentimentos de prazer e } \\
\text { de sofrimento gerados no } \\
\text { trabalho, perante a imple- } \\
\text { mentação de uma mudan- } \\
\text { ça curricular radical. }\end{array}$ & $\begin{array}{l}\text { Trata-se de um estudo } \\
\text { exploratório e descritivo } \\
\text { com abordagem quan- } \\
\text { titativa. Para a coleta de } \\
\text { dados, foi utilizada uma } \\
\text { escala tipo Likert. }\end{array}$ & $\begin{array}{l}\text { A maioria das enfermeiras docentes tem } \\
\text { mais prazer do que sofrimento, pois, } \\
\text { frequentemente, sentem-se valorizadas; } \\
\text { às vezes, sentem-se reconhecidas; outras, } \\
\text { não se sentem desgastadas em suas ati- } \\
\text { vidades na implementação da mudança } \\
\text { curricular radical. }\end{array}$ \\
\hline A4 & 2006 & Medline & $\begin{array}{l}\text { Martins e } \\
\text { Robazzi }^{26}\end{array}$ & $\begin{array}{l}\text { Identificar se as dimen- } \\
\text { sôes de valorização, } \\
\text { desgaste e reconheci- } \\
\text { mento contribuem para } \\
\text { os sentimentos de prazer } \\
\text { e sofrimento na docência } \\
\text { enfermeiras, que viven- } \\
\text { ciaram mudanças no } \\
\text { processo organizativo }\end{array}$ & $\begin{array}{l}\text { Trata-se de um estudo } \\
\text { exploratório e descritivo } \\
\text { com abordagem quan- } \\
\text { titativa. Para a coleta de } \\
\text { dados, foi utilizada uma } \\
\text { escala tipo Likert. }\end{array}$ & $\begin{array}{l}\text { As docentes têm mais prazer que } \\
\text { sofrimento, pois se sentem valorizadas, } \\
\text { reconhecidas e não desgastadas em suas } \\
\text { atividades. Esses dados revelam a im- } \\
\text { portância das relaçôes das docentes com } \\
\text { suas tarefas, colegas e instituição. }\end{array}$ \\
\hline
\end{tabular}

Fonte: Lilacs (2005, 2007, 2009) e Medline (2006). 
A partir da leitura dos artigos selecionados, evidenciou-se como fatores que geram prazer na docência: a valorização no trabalho (A3, A4); o reconhecimento das atividades realizadas (A2, A3, A4); a interação entre docente e aluno (A1, A2); o engajamento com as atividades didático-pedagógicas (A1); o compromisso com a formação profissional (A1). Entre esses fatores, destacam-se a interação entre docente e aluno, a valorização e o reconhecimento profissional; no entanto, as demais evidências também devem ser consideradas e estimuladas, visto que, pelos resultados apresentados nos artigos, também demonstraram ser fontes importantes de prazer.

Estudo $^{27}$ revela como fontes de prazer na docência o orgulho pela atividade exercida, a convivência satisfatória com os estudantes e a inclusáo desses na sociedade por meio da aprendizagem. Outro estudo ${ }^{10}$ confirma que as vivências prazerosas no trabalho se referem, sobretudo, ao relacionamento que os docentes estabelecem com seus pares e alunos e ao reconhecimento profissional - destaca-se a importância disso, que se relaciona à capacidade de dar valor à pessoa e à função executado ${ }^{28}$. Dessa forma, a conquista da identidade social dos profissionais passa pela dinâmica do reconhecimento, ou seja, a cooperação da economia da identidade e da saúde mental no trabalho ${ }^{29}$.

Assim, ele é entendido como uma construção central da identidade de quem o exerce e como um espaço de interação e construção coletiva. Nesse sentido, a dinâmica do reconhecimento assume papel de articulação entre o processo de constituição da identidade e o campo social, pois atribui valor ao trabalho, a partir da interação do trabalhador com o contexto social no qual está inserido, o qual determina a construção da identidade do profissional no campo social ${ }^{28}$.

O prazer e a realização pessoal e profissional advêm da possibilidade de reconhecimento do esforço investido para a realização do serviço ${ }^{29}$. Nesse contexto, a dinâmica do reconhecimento ao trabalhar se mostra fundamental, pois confere a recompensa simbólica para o esforço, a persistência, a resistência ao fracasso e a inteligência mobilizada para a solução dos problemas. Assim, o sujeito exerce suas atividades profissionais com a perspectiva do binômio contribuição/retribuição, ou seja, em troca de seu esforço, espera uma retribuição ${ }^{29}$.

Para isso, o servidor se mobiliza e se engaja em seu ofício, suas açóes necessitam promover uma dinâmica de troca, a fim de possibilitar que os objetivos individuais e coletivos sejam alcançados e, consequentemente, o prazer. Nesse sentido, o trabalho como fonte de prazer e satisfação pessoal advém da valorização e do reconhecimento das açôes realizadas ${ }^{30}$. Isso demonstra o prazer proporcionado quando é compatível o conteúdo da tarefa e os desejos inconscientes do profissional ${ }^{29,31}$.
Desse modo, é fundamental que o profissional seja reconhecido e valorizado ao desempenhar suas funçôes pois, através de suas competências e habilidades, ele contribui para a organização do trabalho e para a constituição de sua própria subjetividade ${ }^{26}$. Assim, o prazer é uma consequência da organizaçáo do trabalho coletivo, com respeito às diferenças de cada ser humano ${ }^{32}$.

Entende-se por reconhecimento a capacidade de valorização à pessoa e à função executada, bem como o retorno que se obtém deste ${ }^{28}$. Dessa forma, quando a qualidade do trabalho é reconhecida, os esforços, as angústias, as decepçôes e os desânimos do profissional adquirem sentido, na medida em que o reconhecimento possibilita transformar em prazer o sofrimento vivenciado pelos profissionais ${ }^{12}$. Cabe destacar que, para que o trabalho opere como fonte de saúde, é necessário o reconhecimento daquele que o exerce, uma vez que no profissional reside a possibilidade de dar sentido ao sofrimento vivenciado. Esse reconhecimento pode ocorrer tanto pelo grupo de trabalho, pelos superiores hierárquicos ou clientes ${ }^{17}$.

Destarte, depende do reconhecimento o sentido dado ao sofrimento no trabalho, isto é, quando a qualidade deste é reconhecida, o servidor percebe que suas dúvidas, decepçóes e desânimos têm sentido, o que faz dele um sujeito diferente daquele que era antes do reconhecimento ${ }^{33}$. Assim, o reconhecimento pode acontecer como constataçáo, quando se considera a realidade e a contribuição individual à organização do trabalho, ou como gratidão, expressando-se pela contribuição dos profissionais à organização de seu ofício ${ }^{34}$. Além disso, o reconhecimento pode ser distinguido em julgamentos de utilidade e estética, ambos tratando do trabalho realizado. O julgamento de utilidade é aquele executado verticalmente por superiores hierárquicos, subordinados e, eventualmente, clientes; enquanto o julgamento de estética é aquele executado horizontalmente, por pares, colegas, membros da equipe ou comunidade ${ }^{34}$.

Quando o reconhecimento acontece, o trabalhador se sente aceito, admirado, com liberdade para se expressar, se construir e se manifestar diante das situaçóes de seu emprego, e não só para produzir ${ }^{35}$. Assim, o reconhecimento do trabalho é proveniente da articulação entre visibilidade, apreciação e julgamento de utilidade sobre o profissional e o produto de suas atividades, a partir das quais ele se sente reconhecido pelos colegas e pela sociedade ${ }^{29}$.

Com relaçáo ao sofrimento na docência de enfermagem, emergiram como fatores: sobrecarga de trabalho (A2); desarticulação entre o empenho do docente e do aluno, marcado por desinteresse ou descompromisso (A1); questóes relacionadas à organização do trabalho (A1); relacionamento interpessoal (A1, A2); falta de recursos materiais e humanos (A2); baixos salários (A2); desconforto do ambiente físico (A2); falta 
de privacidade (A2). Destaca-se o relacionamento interpessoal como o principal fator, no entanto, as demais evidências também são fontes relevantes de sofrimento.

Estudo com trabalhadores de enfermagem de um serviço de hemodiálise identificou como fatores de sofrimento as dificuldades de relacionamento com os colegas de profissão e a falta de comprometimento de alguns membros da equipe ${ }^{36}$. Estudo realizado com docentes universitários de instituições públicas acerca da sua saúde e do modo de vida identificou que o relacionamento com colegas é marcado pela competição, rivalidade ou falta de companheirismo ${ }^{37}$. Portanto, percebe-se que o relacionamento interpessoal interfere diretamente no cotidiano de trabalho, pois exercer atividades profissionais pressupóe colaborar com uma hierarquia organizacional e com os colegas, sendo preciso interagir para atingir o objetivo de produção de um bem ou serviço ${ }^{38}$.

Nessa perspectiva, um ofício prazeroso é aquele que se desenvolve em um ambiente agradável e com relaçôes interpessoais construtivas, pois a partir do momento em que os trabalhadores não encontram apoio e respaldo entre os seus pares, exercer a profissáo perde o seu sentido. Dessa forma, um conflito gerado no grupo de trabalho pode ser positivo se estimula a busca de soluçôes para um determinado problema. Do contrário, se a situação de conflito implica na falta de coesão, ela poderá causar frustração e insatisfação no profissional ${ }^{39,40}$. Assim, o essencial para a saúde mental individual nas relaçôes de trabalho é a ação sobre o funcionamento do coletivo, pois uma das grandes causas de sofrimento nesse meio está na má qualidade dessas relaçóes ${ }^{41}$.

Nesse sentido, o sofrimento ao exercer a atividade profissional pode estar associado à vontade de realizar bem o ofício e à pressão para aumentar a sua produtividade $^{42}$. Estudo realizado com docentes do ensino superior confirmam o sofrimento advindo das condiçôes inadequadas de serviço ${ }^{43}$. Para a psicodinâmica do trabalho, o sofrimento pode ser criativo ou patogênico. No criativo, o profissional mobiliza-se transformando o seu sofrimento em algo benéfico para ele; já o patogênico, relaciona-se à ausência de flexibilização da organização do trabalho ${ }^{35}$. Assim, quando o sofrimento pode ser transformado com criatividade, ele ocasiona uma contribuição que beneficia o servidor, aumentando a sua resistência ao risco de desestabilização psíquica e somática. No entanto, quando o sofrimento se estabelece no sentido patogênico, o ofício se transforma em um mediador da desestabilização e da fragilização da saúde ${ }^{12}$.

Portanto, percebe-se que na docência de enfermagem emergem tanto sentimentos de prazer quanto de sofrimento, pois os docentes compreendem seu ofício como fonte de sofrimento ou de prazer, expressando assim as contradições e ambiguidades de suas vivências atuais no meio acadêmico ${ }^{10}$. Desse modo, esses resultados vão ao encontro da ideia de que o trabalho nunca é neutro em relação à saúde, pois pode gerar sentimentos diversos, ora sofrimento, ora prazer, favorecendo a doença ou a saúde ${ }^{12}$.

\section{Conclusão}

A partir da construção desta revisão integrativa, abordando os fatores que geram prazer e sofrimento no trabalho de docentes de enfermagem, foi possível constatar que tais sentimentos aparecem interligados, pois são fortemente influenciados pelas relaçóes no trabalho. Evidenciou-se, por intermédio da pesquisa, que os principais fatores que geram prazer no trabalho de docentes de enfermagem são a interação entre docente e aluno, a valorização e o reconhecimento profissional; e, como principal fator de sofrimento, o relacionamento interpessoal. No entanto, não se desconsidera as demais evidências, visto que todas são de suma importância na relação entre trabalho e docentes de enfermagem.

Apesar de existirem textos publicados referentes ao processo do trabalho do docente vistos desde o relacionamento, a prática pedagógica, o componente institucional e a valorização do trabalho profissional, constatou-se que existe uma lacuna nas pesquisas concernentes a essa temática, pois foram encontrados poucos estudos que atendessem aos critérios de inclusão e exclusão, o que mostra a relevância deste artigo para constituir novas pesquisas, com maior aprofundamento e das quais possam emergir contribuiçôes para a área da enfermagem, principalmente para o trabalho docente na contemporaneidade.

As limitaçóes mencionadas, assim como os resultados encontrados, suscitam a realizaçáo de novos estudos, a fim de que os resultados possam ser confrontados, rediscutidos e ampliados. Ratifica-se a necessidade de a enfermagem docente superar os desafios que ainda persistem e causam sofrimento no trabalho. Compreendese que evidenciar as contribuiçóes das pesquisas científicas produzidas acerca dos fatores que geram prazer e sofrimento na docência de enfermagem pode contribuir para que esses profissionais possam ressignificar suas vivências de sofrimento na busca pelo prazer na docência.

\section{Referências}

1. Glanzner $\mathrm{CH}$, Olschowsky A, Kantorski LP. O trabalho como fonte de prazer: avaliação da equipe de um Centro de Atenção Psicossocial. Rev Esc Enferm USP. 2011;45(3):716-21. 
2. Mendonça $\mathrm{H}$, Mendes AM. Percepção de justiça e saúde mental no trabalho [Internet]. In: Ferreira JJ, Penido LO. Anais do $1^{\circ}$ Congresso Internacional sobre Saúde Mental no Trabalho; 2004; Goiânia. Goiânia: Cir Gráfica; 2013 [citado em 2017 set 28]. p. 157-75. Disponível em: https://goo.gl/wgXP55.

3. Kessler AI, Krug SBF. Do prazer ao sofrimento no trabalho da enfermagem: o discurso dos trabalhadores. Rev Gaúcha Enferm. 2012;33(1):49-55.

4. Costa MCV. Trabalho docente e profissionalismo: uma análise sobre gênero, classe e profissionalismo no trabalho de professoras e professores de classes populares. Porto alegre: Sulina; 1995.

5. Tardif M, Lessard MC. O trabalho docente: elementos para uma teoria da docência como profissão de interaçóes humanas. 4a ed. Petrópolis: Vozes; 2008.

6. Morosini MC, organizadora. Professor do ensino superior: identidade, docência e formação. Brasília: Instituto Nacional de Estudos e Pesquisas Educacionais; 2000.

7. Geraldi CMG, Fiorentini D, Pereira EMA. Cartografias do trabalho docente. Campinas: Mercado de Letras; 2001.

8. Zaragoza JME. O mal-estar docente: a sala de aula e a saúde dos professores. Bauru: Edusc; 1999.

9. Trindade N, Bonito J. O adoecimento do trabalhador docente do ciclo básico I e II da escola pública municipal de Belém (Pará, Brasil) no distrito administrativo do entroncamento [comunicação oral]. Viseu; 2011 [citado em 2017 set 27]. Disponível em: https://goo.gl/hx7ttq.

10. Coutinho MC, Dal Magro MLP, Budde C. Entre o prazer e o sofrimento: um estudo sobre os sentidos do trabalho para professores universitários. Psicol Teor Prat. 2011;13(2):154-67.

11. Merlo ARC, Barbarini N. Reestruturação produtiva no setor bancário brasileiro e sofrimento dos caixas executivos: um estudo de caso. Psicol Soc. 2002;14(1):103-22.

12. Dejours C, Abdoucheli E, Jayet C. Psicodinâmica do trabalho: contribuiçóes da escola dejouriana à análise da relação prazer, sofrimento e trabalho. São Paulo: Atlas; 2011.

13. Machado AG, Merlo ARC. Cuidadores: seus amores e suas dores. Psicol Soc. 2008;20(3):444-52.

14. Dejours C. A loucura do trabalho: estudo de psicopatologia do trabalho. 5a ed. São Paulo: Cortez; 1992.

15. Barros PCR, Mendes AMB. Sofrimento psíquico no trabalho e estratégias defensivas dos operários terceirizados da construção civil. Psico-USF. 2003;8(1):63-70.

16. Spode CB, Merlo ARC. Trabalho policial e saúde mental: uma pesquisa junto aos capitães da Polícia Militar. Psicol Refl Crít. 2006;19(3):362-70.

17. Mendes AMB, Vieira AP, Morrone CF. Prazer, sofrimento e saúde mental no trabalho de teleatendimento. RECADM. 2009;8(2):151-8.

18. Mendes AM, Tamayo A. Valores organizacionais e prazer-sofrimento no trabalho. Psico-USF. 2001;6(1):39-46.

19. Mendes KDS, Silveira RCCP, Galvão CM. Revisão integrativa: método de pesquisa para a incorporaçáo de evidências na saúde e na enfermagem. Texto Contexto Enferm. 2008;17(4):758-64.

20. Souza MT, Silva MD, Carvalho R. Revisão integrativa: o que é e como fazer. Einstein. 2010;8(1):102-6.

21. Bardin L. Análise de conteúdo. 8a ed. Lisboa: Ediçôes 70; 2011.

22. Fineout-Overholt E, Melnyk BM, Schultz A. Transforming health care from the inside out: advancing evidence-based practice in the 21st century. J Prof Nurs. 2005;21(6):335-44.

23. Ferreira EM, Fernandes MFP, Prado C, Baptista PCP, Freitas GF, Bonini BB. Prazer e sofrimento no processo de trabalho do enfermeiro docente. Rev Esc Enferm USP. 2009; 43(Esp 2):1292-6.

24. Carbogim FC, Gonçalves AMC. Docentes de enfermagem: prazer e sofrimento no trabalho. REME. 2007;11(3):291-6.

25. Martins JT, Robazzi MLCC. Implementação de um currículo com mudança radical: sentimentos de prazer e sofrimento. Cogitare Enferm. 2005;10(2):29-35.

26. Martins JT, Robazzi MLCC. Sentimentos de prazer e sofrimento de docentes na implementação de um currículo. Rev Gaúcha Enferm. 2006;27(2):284-90.

27. Carvalho MVB, Garcia FC. Prazer e sofrimento no trabalho de professores do ensino fundamental e médio: estudo de caso em uma escola estadual da cidade de CurveloMG [Internet]. Anais do XIV SEMEAD: Seminários em Administração FEA-USP; 2011; São Paulo. São Paulo: Universidade de São Paulo; 2011 [citado em 2017 set 27]. Disponível em: https://goo.gl/8XWxmj.

28. Morrone CF, Mendes AM. A ressignificação do sofrimento psíquico no trabalho informal. Rev Psicol Organ Trab. 2003;3(2):91-118.

29. Dejours C, Abdoucheli E, Jayet C. Psicodinâmica do trabalho, contribuiçóes da escola dejouriana à análise da relação prazer, sofrimento e trabalho. São Paulo: Atlas; 2014.

30. Azambuja EP, Fernandes GFM, Kerber NPC, Silveira RS, Silva AL, Gonçalves LHT, et al. Significados do trabalho no processo de viver de trabalhadoras de um programa de saúde da família. Texto Contexto Enferm. 2007;16(1):71-9.

31. Mendes $\mathrm{AMB}$, organizadora. Psicodinâmica do trabalho: teoria, método e pesquisas. São Paulo: Casa do Psicólogo; 2007. 360 p.

32. Dejours C. Psicopatologia à psicodinâmica do trabalho. $1^{\mathrm{a}}$ ed. Brasília: Paralelo 15; 2004.

33. Traesel ES, Merlo ARC. A psicodinâmica do reconhecimento no trabalho de enfermagem. Psico. 2009;40(1):102-9.

34. Lancman S, Sznelwar LI, organizadores. Christophe Dejours: da Psicopatologia à Psicodinâmica do Trabalho. $3^{\text {a }}$ ed. Rio de Janeiro: Fiocruz; 2011.

35. Freitas LG, coordenadora. Prazer e sofrimento no trabalho docente: pesquisas brasileiras. Curitiba: Juruá; 2013.

36. Prestes FC, Beck CLC, Silva RM, Tavares JP, Camponogara $S$, Burg G. Prazer-sofrimento dos trabalhadores de enfermagem de um serviço de hemodiálise. Rev Gaucha Enferm. 2010;31(4):738-45. 
37. Borsoi ICF. Trabalho e produtivismo: saúde e modo de vida de docentes de instituiçôes públicas de Ensino Superior. Cadernos de Psicologia Social do Trabalho. 2012;15(1):81-100.

38. Gernet I, Dejours C. Avaliação do trabalho e reconhecimento. In: Bendassolli PF, Soboll LAP, organizadores. Clínicas do trabalho. São Paulo: Atlas; 2011.

39. Tolfo SR, Piccinini V. Sentidos e significados do trabalho: explorando conceitos, variáveis e estudos empíricos brasileiros. Psicol Soc. 2007;19(Supl 1):38-46.
40. Baggio MA, Formaggio FM. Trabalho, cotidiano e o profissional de enfermagem: o significado do descuidado de si. Cogitare Enferm. 2008;13(1):67-74.

41. Dejours C. Banalização da injustiça social. São Paulo: Fundação Getúlio Vargas; 1999. 160 p.

42. Assunção AA, Oliveira DA. Intensificação do trabalho e saúde dos professores. Educ Soc. 2009;30(107):349-72.

43. Silva FG. O professor e a educação: entre o prazer, o sofrimento e o adoecimento. Revista Espaço Acadêmico. 2011; XI(124):57-66.

\section{Como citar este artigo:}

Fernandes MNS, Lopes LFD, Coronel DA, Weiller TH, Viero V, Freitas PH. Prazer e sofrimento no trabalho de docentes de enfermagem: revisão integrativa. Rev. Aten. Saúde. 2017;15(53):95-102. 